\title{
Improvement of Asphalt Properties Using Polymethyl Methacrylate
}

\author{
Reda A. Haggam 1*, Ismail M. Ibrahim², Mohamed El-Shafie Abdelatif', \\ Abd El Latief M. Abd Elrhman², Sanaa A. El-Kholy² \\ ${ }^{1}$ Department of Chemistry, Faculty of Science, Zagazig University, Zagazig, Egypt \\ ${ }^{2}$ Egyptian Petroleum Research Institute (EPRI), Nasr City, Cairo, Egypt \\ Email: rhaggam@yahoo.com
}

Received 24 February 2014; revised 24 March 2014; accepted 2 April 2014

Copyright (C) 2014 by authors and Scientific Research Publishing Inc.

This work is licensed under the Creative Commons Attribution International License (CC BY).

http://creativecommons.org/licenses/by/4.0/

(c) (i) Open Access

\section{Abstract}

Increasing traffic loading and volumes on roads have led to the use of polymer modified binders to improve the performance of bitumen in terms of strength, durability, and resistance to rutting. This research studies the effect of adding poly methyl methacrylate (PMMA) with different molecular weights on asphalt properties. PMMA polymer was prepared via solution polymerization of MMA using dibenzoyl peroxide (DBPO) as initiator. By controlling the time of reaction, two different molecular weights were obtained: PMMA1 and PMMA2 with Mw 21.000 and 30.000, respectively. The morphological studies of polymer modified binder were discussed. Physical properties of PMMA modified asphalt including penetration value, softening point, and kinematic viscosity at $135^{\circ} \mathrm{C}$ and $150^{\circ} \mathrm{C}$ were examined. The aging properties of polymer modified asphalts were examined using thin film oven test (TFOT). A hot storage stability test was carried out for polymer modified binder. Indirect tensile strength (ITS) test and durability performance of modified asphalts were evaluated using Marshall Test. Resilient modulus (RM) test was evaluated using Universal Testing Machine. Results showed that the inclusion of PMMA polymer in asphalt binder has significantly improved its properties. The achieved improvement was found to be dependent on polymer molecular weight. Moreover, the results explained that the compatibility between PMMA and asphalt binder is improved upon further aging especially with low molecular weight polymer (PMMA).

\section{Keywords}

Asphalt Binder, Rutting, PMMA, TFOT, Ageing

\footnotetext{
"Corresponding author.
} 


\section{Introduction}

Traditionally, conventional binders, such as binder with 100 penetration grade (100 pen.) and 60 penetration grades (60 pen.), were used in road pavement construction. However, increased axle loading, and braking power of vehicles in recent years required the durability and strength of the binder to resist rutting, fatigue, and cracking tendencies of road pavements. One means of achieving this is to modify the bitumen with polymers [1]. The addition of polymers, chains of repeated small molecules, to asphalt has been shown to improve performance. Pavement with polymer modification exhibits greater resistance to rutting and thermal cracking, and decreases fatigue damage, stripping, and temperature susceptibility. Polymers that are used for asphalt modification can be grouped into three main categories: thermoplastic elastomers, plastomers and reactive polymers. Thermoplastic elastomers are obviously able to confer good elastic properties on thermomodified binder; while plastomers and reactive polymers are added to improve rigidity, and reduce deformations under load. Belonging to the first category, styrene-butadiene-styrene block (SBS) copolymers are probably the most frequently used asphalt modifiers for paving applications [2]-[5]. Examples of the plastomeric types of polymers were studied since asphalt modifications are polyethylene (PE), and ethylene-butyl acrylate (EBA) random copolymers [6]-[9]. Due to its low compatibility with asphalt, PE is not widely used for paving applications, and thus ethylene copolymersare preferred. Recently, reactive polymers have been introduced as asphalt modifiers. Their "reactivity" is due to the presence of functional groups supposedly able to bond with asphalt molecules. Polarity of the polymer can enhance its solubility and compatibility with base bitumen. Polar groups present in the polymer molecules can react with the polar constituents of bitumen. Subsequently, phase separation is prevented, which in turn enhances the materials consistency, and decreases oxidative ageing [10]-[13]. Among polar polymers, a very limited number of studies discuss the fundamental properties of modified bitumens with acrylate polymers. Most frequently used acrylates as bitumen modifying agents in road applications are ethylene vinyl acetate (EVA) glycidyl methacrylate (EA) terpolymer, ethylene butyl acrylate (EBA) copolymer, etc. [14]-[16]. In this research, different molecular weights from PMMA were added to asphalt for improving the performance of bitumen in terms of strength, durability, and resistance to rutting.

\section{Experimental}

\section{Materials}

Methyle methacrylate monomer (MMA) was supplied by Navol, Dibenzoylperoxide (DBPO) was obtained from Merck, Toluene and methanol solvents were obtained from Carloerba reagents. Local asphalt of penetration grade 60/70, produced by El-Nasser Petroleum Company, Suez-Egypt. The crushed Limestone aggregate, limestone mineral filler, and crushed sand were originally obtained from Ataka Suez-Egypt. The physical properties of the asphalt binder and the aggregate are given in Table 1 and Table 2, respectively. Aggregate gradation is also provided in Table 3.

Table 1. Physical properties and chemical constituents of asphalt cement 60/70.

\begin{tabular}{lc}
\multicolumn{1}{c}{ Properties } & Values \\
\hline Physical properties: & 60 \\
-Penetration at $25^{\circ} \mathrm{C} 100 \mathrm{~g}, 5$ seconds, $0.1 \mathrm{~mm}$ & 346 \\
-Kinematics viscosity at $135^{\circ} \mathrm{C}$, C.st. & 2122 \\
-Absolute viscosity at $60^{\circ} \mathrm{C}$, poise. & 250 \\
-Flash point, ${ }^{\circ} \mathrm{C}(\mathrm{Cleveland}$ open cup) & +100 \\
-Ductility at $25^{\circ} \mathrm{C}, 5 \mathrm{~cm} / \mathrm{min}, \mathrm{cm}$ & 52 \\
-Softening point ${ }^{\circ} \mathrm{C}($ Ring and Ball) & 99.9 \\
-Solubility in trichloroethylene, $\%$ & \\
Chemical constituents & 26.2 \\
Oil fractions & 48.4 \\
Resins fractions & 25.4 \\
Asphaltenes fractions & \\
\hline
\end{tabular}


Table 2. Physical properties of aggregates.

\begin{tabular}{ccc}
\hline Properties & Coarse & Fine \\
\hline Average bulk specific gravity (dry) $\left(\mathrm{g} / \mathrm{cm}^{3}\right)$ & 2.79 & 2.73 \\
Average bulk specific gravity (SSD) $\left(\mathrm{g} / \mathrm{cm}^{3}\right)$ & 2.81 & 2.77 \\
Average absorption (\%) & 0.61 & 1.57 \\
\hline
\end{tabular}

Table 3. Gradation of the aggregate.

\begin{tabular}{ccc}
\hline & Ranged of Standards & \\
\hline Sieve size $(\mathrm{mm})$ & Passing (\%) & Retained (\%) \\
\hline 25 & 0 & 0 \\
19 & $82-100$ & 9 \\
12.5 & $68-87$ & 13 \\
9.5 & $60-79$ & 8 \\
4.75 & $46-65$ & 14 \\
2.36 & $34-51$ & 13 \\
0.425 & $17-29$ & 20 \\
0.180 & $9-18$ & 9 \\
0.075 & $2-7$ & 9 \\
Pan & 0 & 5 \\
\hline
\end{tabular}

\section{Methods of Preparation}

\subsection{Solution Polymerization of Methyl Methacrylate [17]}

Polymerization was performed in glass reactor $(1000 \mathrm{~mL})$ equipped with a mixing system and thermostated at $90^{\circ} \mathrm{C}$, using a monomer solution contained MMA (40\%, wt/wt) and toluene solvent. After attaining constant temperature, $0.5 \mathrm{wt} \%$ of (DBPO) was added. Two different molecular weights of PMMA polymers were obtained by controlling the time of reaction since the termination reaction is time dependent [18]. In predetermined intervals solution $(5 \mathrm{~mL})$ was removed, mixed with of methanol $(100 \mathrm{~mL})$ and after staying overnight at room temperature, the precipitate was filtered off, washed with methanol, dried and weighed. Each experiment was performed at least three times.

\subsection{Preparation of Modified Asphalt Binder with Methyl Methacrylate}

The polymer modified asphalt binders were prepared using a high shear mixer. First, asphalt (500 g) was heated until it became a fluid in an iron container, then upon reaching about $150^{\circ} \mathrm{C}$, a weighed amount of polymer was slowly added to the asphalt polymer content is always, $4 \%, 5 \%, 6 \%, 7 \%$, and $8 \%$ respectively, the shearing temperature was $150^{\circ} \mathrm{C}$, and the shearing rate was $4000 \mathrm{rpm}$. Mixing was continued at $150^{\circ} \mathrm{C}$ for 2 hrs to produce homogeneous mixtures. After completion, the polymer modified asphalt was removed from the container and divided into small containers. The blend was cooled to ambient temperature, sealed with aluminum foil, and stored for further testing.

\section{Testing Procedures}

The principal test methods on the reheated modified blends and base asphalt include:

\subsection{Binder Tests}

Tests determining the physical properties of asphalts were performed, including penetration test at $25^{\circ} \mathrm{C}$ according to ASTM D5-97 [19] Softening point (Ring and Ball) according to ASTM D36-95 [20], and kinematic vis- 
cosity (C.st) at $135^{\circ} \mathrm{C}$ and $150^{\circ} \mathrm{C}$ according to ASTM D-2170 [21]. Thin Film Oven Test (TFOT): The procedure according to ASTM D1754 [22] was developed to simulate the effect of heating in a hot-mix plant operation on asphalt cement. In the standard TFOT procedure, the asphalt cement sample is poured into a flat-bottomed pan to a depth of about $3.2 \mathrm{~mm}$. The pan with the asphalt sample is then placed on a rotating shelf in an oven, and kept at a temperature of $163^{\circ} \mathrm{C}$ for 5 hrs. The properties of the asphalt before and after the TFOT procedure are measured to determine the change in properties that might be expected after a hot-mix plant operation Table 4 .

\subsection{Hot Storage Stability Test According to ASTM Standard}

An aluminum foil tube, $35 \mathrm{~mm}$ diameter and $190 \mathrm{~mm}$ height, was filled with about $90 \mathrm{gm}$ homogenous polymer modified binder. After closing the tube, it was stored vertically at $180^{\circ} \mathrm{C}$ for three days. The tube with the modified binder was cooled to ambient temperature and then to about $-10^{\circ} \mathrm{C}$, after which the foil was peeled off and the modified binder specimen cut horizontally into three equal sections. The samples taken from the top and the bottom of the tube were used to evaluate the storage stability of the binder by measuring their softening point, penetration, and dynamic rheological properties.

\subsection{Marshall Test}

Marshall Test method was carried out on all modified and unmodified asphalt mixes (asphalt binder with aggregates) according to ASTM D-1559 [23]. Two principal features of the Marshall method of mix design are the density-voids analysis, and stability-flow test of the compacted test specimens. The stability of the test specimen is the maximum load resistance that the standard test specimen will develop at $60^{\circ} \mathrm{C} \pm 1^{\circ} \mathrm{C}$ when tested as outlined. The flow value is the total movement or strain, in units of $0.25 \mathrm{~mm}$, occurring in the specimen between no load and maximum load during the stability test. Six different asphalt mixes were prepared for each modified binder beside the control binder using $4 \%, 4.5 \%, 5 \%, 5.5 \%, 6 \%$ and $6.5 \%$ weight of aggregates. Both faces of the specimen are compacted with 75 blows. Samples were extruded from molds and left to cool down before starting test at constant temperature, $25^{\circ} \mathrm{C}$ for $24 \mathrm{hrs}$, and then extracted from the mold by using a hydraulic system. The samples were left at $60^{\circ} \mathrm{C} \pm 1^{\circ} \mathrm{C}$ for $30 \mathrm{~min}$. Each reading is the average of three specimens. Stability and flow were measured at $60^{\circ} \mathrm{C} \pm 1^{\circ} \mathrm{C}$.

\subsection{Indirect Tensile Strength (ITS) Test}

The indirect tensile strength (ITS) test was carried out to define the tensile characteristics of the asphalt concrete mixes, which can be further related to the cracking properties of the pavement [24]. The indirect tensile strength (ITS) of water conditioned as well as unconditioned dry specimen (both unmodified and modified asphalt mix) was determined using Marshall Test apparatus. The ITS test was calculated using Equation (1):

$$
\text { ITS }=2 \mathrm{P}_{\max } / \pi \mathrm{td}
$$

(calculation of ITS)

where, $P_{\max }$ is the maximum load $(\mathrm{kg}), \mathrm{t}$ is the thickness of the specimen $(\mathrm{cm}), \mathrm{d}$ is the diameter of the specimen (cm).

The tensile strength ratio (TSR), which is the ratio of the tensile strength of water conditioned specimen, (ITS wet, $60^{\circ} \mathrm{C}, 24 \mathrm{~h}$ ) to the tensile strength of unconditioned specimen (ITS dry), has been evaluated according to AASHTO T283 [25].

\subsection{Resilient Modulus (RM) Test}

Resilient modulus (RM) is one of the important mechanical properties used to design asphalt pavement struc-

Table 4. Phase separation of 7\% polymer modified binder.

\begin{tabular}{|c|c|c|c|c|c|c|}
\hline & \multicolumn{3}{|c|}{ Top samples } & \multicolumn{3}{|c|}{ Bottom samples } \\
\hline & Softening point & Penetration & Viscosity & Softening point & Penetration & Viscosity at $135^{\circ} \mathrm{C}$ \\
\hline PMMA1 & 68 & 40 & 910 & 70 & 38 & 907 \\
\hline PMMA2 & 60 & 50 & 989 & 63 & 48 & 984 \\
\hline
\end{tabular}


tures. It is defined as the ratio of the repeated stress to the corresponding resilient strain. Since the recoverable portion of the strain is measured in a resilient modulus test, the stiffness of the material can be related to the modulus of elasticity of the asphalt mix and commonly used for mechanistic analysis [26]. Therefore, the resilient modulus of both unmodified and modified asphalt mixes was studied at different temperatures for predicting the mixture design and pavement performance. The total resilient modulus $\left(\mathrm{E}_{\mathrm{RT}}\right)$ is defined in Equation (2):

$$
\mathrm{E}_{\mathrm{RT}}=\left(v_{\mathrm{RT}}+0.27\right) / \mathrm{t} \Delta \mathrm{H}_{\mathrm{T}} \quad \text { (The total resilient modulus }\left(\mathrm{E}_{\mathrm{RT}}\right) \text { definition) }
$$

where, $\mathrm{P}$ is the repeated load $(\mathrm{N}), v_{\mathrm{RT}}$ the total resilient Poisson's ratio (a value of normally 0.35 used), $\mathrm{t}$ is the thickness of specimen ( $\mathrm{mm}$ ) and $\Delta \mathrm{H}_{\mathrm{T}}$ is the total recoverable horizontal deformation (mm).

The test was done on Universal Testing Machine according to ASTM D 4123-82 [27]. The test was conducted by applying the compressive load at $5^{\circ} \mathrm{C}, 25^{\circ} \mathrm{C}, 35^{\circ} \mathrm{C}$ and $45^{\circ} \mathrm{C}$ for $7 \%$ polymer modified and unmodified asphalt mixes. Three laboratory fabricated Marshall specimens were tested. Prior to testing, three dimensional axes were marked on the specimen and height of the sample was determined. The specimens were conditioned for 24 hrs in the environmental chamber at the given temperature and then subjected to repeated loading (pulse width of 100 mms, pulse repetition period of $3000 \mathrm{mms}$ and test pulse count of five).

\subsection{Plastic Deformation Test (Rutting)}

Plastic deformation (Rutting) test method was carried out on modified mixtures (PMMA1 and, PMMA2) and unmodified asphalt mixtures. Rut depth was determined using the wheel tracking machine (WTT).

\subsection{Technical Specification}

Specimen dimension: $44.4 \times 33.5 \mathrm{~cm}$, and $5 \mathrm{~cm}$ thickness. Tracking wheel: $20 \mathrm{~cm}$ diameter and $4.56 \mathrm{~cm}$ width, with a tire of a solid rubber load on the wheel of $6.25 \mathrm{~kg}$ was normally employed. Motion of specimen: a motor and a reciprocating device give the table a motion of 42 passes per minute with a distance of $33 \mathrm{~cm}$. Rutting depth: rutting depth is recorded at the midpoint of the specimen length.

Wheel tracking and specimen were maintained at $60^{\circ} \mathrm{C} \pm 1^{\circ} \mathrm{C}$ in a metal box of the machine for about 5 hrs before testing to ensure a constant temperature during testing. The temperature of the test was $60^{\circ} \mathrm{C} \pm 1^{\circ} \mathrm{C}$. The zero reading deformation of the dial gauge was taken when the wheel touches the edge of the specimen. The wheel was allowed to pass on the sample, as previously mentioned, 42 passes per minute with a distance of travel of $33 \mathrm{~cm}$. Rutting depth deformation was recorded at 5 min intervals at the midpoint of the specimen length. Measurement was made for the track depth up to $60 \mathrm{~min}$.

\section{Results and Discussion}

We offer in this article studies on the effect of adding poly methyl methacrylate (PMMA) with different molecular weights on the properties of asphalt. PMMA polymer was prepared via solution polymerization of MMA using dibenzoyl peroxide (DBPO) as initiator. By controlling the time of reaction, two different molecular weights were obtained: PMMA1 and PMMA2 with Mw 21.000 and 30.000, respectively as shown in Table 5(a), Table 5(b).

Table 6 illustrates flow values versus optimum binder content. The addition of polymer to base asphalt may import more flexibility to asphalt concrete mixtures. This flexibility will consequently increase the flow of the

Table 5. (a) GPC of PMMA1; (b) GPC of PMMA2.

(a)

\begin{tabular}{cccccccc}
\hline & Retention time & Mn & Mw & MP & Mz (Daltons) & Mz + 1 (Daltons) & Poly-dispersity \\
\hline 1 & 24.061 & 13,400 & 21.000 & 20,604 & 28,821 & 35,776 & 1.570 \\
\hline
\end{tabular}

(b)

\begin{tabular}{cccccccc}
\hline & Retention time & Mn & Mw & MP & Mz (Daltons) & Mz + 1 (Daltons) & Poly-dispersity \\
\hline 1 & 23.079 & 18,400 & 30.000 & 31,852 & 41,547 & 51,030 \\
\hline
\end{tabular}


Table 6. Effect of modifier type and modifier content on Marshall test results.

\begin{tabular}{ccccc}
\hline Mix No. & Polymer content (\%) & Asphalt content (\%) & Stability (N) & Flow (mm) \\
\hline Control & 0 & 5.2 & 8690 & 2.75 \\
& 4 & & 9750 & 2.98 \\
& 5 & & 10,020 & 3.12 \\
PMMA1 & 6 & 5.5 & 10,600 & 3.30 \\
& 7 & & 11,120 & 3.41 \\
& 8 & & 11,255 & 2.78 \\
PMMA2 & 4 & 8955 & 2.82 \\
& 5 & 5.5 & 9250 & 2.90 \\
\hline
\end{tabular}

compacted mix under loads. According to these results, the flow value increased with increasing the polymer percent added to with control binder. The percentage of flow value increases ranged between $8 \%$ and $24 \%$ with the addition of $4 \%$ to $7 \%$ of PMMA1 respectively compared with the control mixture.

\subsection{Morphological Study of Base Asphalt and Modified Binder}

The SEM photos of the virgin and polymers modified binder (for 7\% polymer addition) are displayed in Figures 1(a)-(c) The light phase shown in the picture represents the unreacted but only swollen polymer in resins fractions and the dark phase is the asphalt. By comparing the figures (a, b, and c), it is observed that in the numbers and size of light phase are very low and small in Figure 1(a) and increase in Figure 1(b), Figure 1(c) which indicate a good compatibility and reactivity with asphalt binder in case of PMMA1 with low molecular weight. Since in using of low molecular weight polymer as the number of active group increases the possibility of reactivity increases as well. In addition the shorter the chain of the polymer, the easier of its dispersion in the colloidal structure of asphalt

\subsection{Hot Storage Stability}

The phase separation of PMMA modified bitumen was studied using hot storage stability test. At a given polymer content (7\%) the storage stability increases with decreasing the length of polymer chains. Since the difference between the values in the top and the bottom are in limits of ASTM standard compared with the polymers of high molecular weights that are out of limits of standard. So (PMMA1) displays good dispersion and interaction with asphalt and consequently, a lower phase separation was observed during hot storage.

\subsection{Penetration}

Figure 2 shows the variation of penetration values with the various percentages of polymers added to asphalt. The figure indicates that the penetration value decreases as the polymer content increases in the mixture. Reduction in penetration value ranges from $11 \%$ to $37 \%$ with the addition of $4 \%$, and $7 \%$ of PMMA1, respectively, while it ranges from $6.6 \%$ to $23 \%$ with the addition of $4 \%$ and $7 \%$ of PMMA2, respectively, compared to the original asphalt. Furthermore, results indicated that no significant difference between $7 \%$ and $8 \%$ of polymer content. This means that the addition of polymer makes the modified asphalt harder and more consistent, which might improve the rutting resistance of the mixture, but on the other hand, it might affect flexibility of the bitumen by making the asphalt much stiffer, and thus the resistance to fatigue cracking can be affected.

\subsection{Softening Point}

Figure 3 shows that the softening point increases with increasing polymer content. It appears clearly from the 


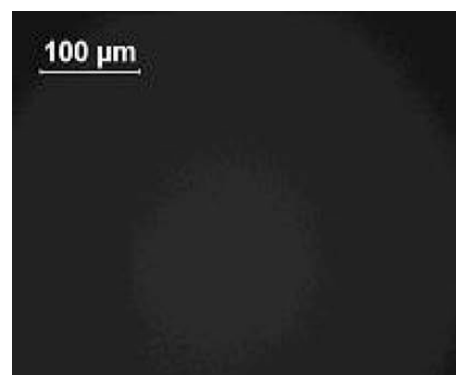

(a)

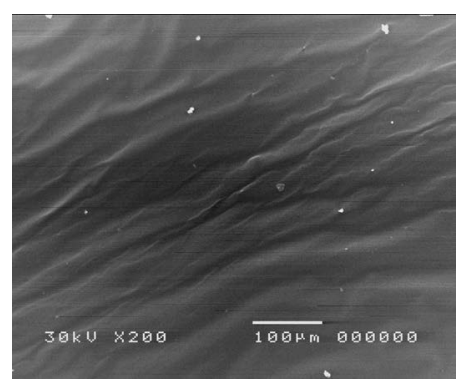

(b)

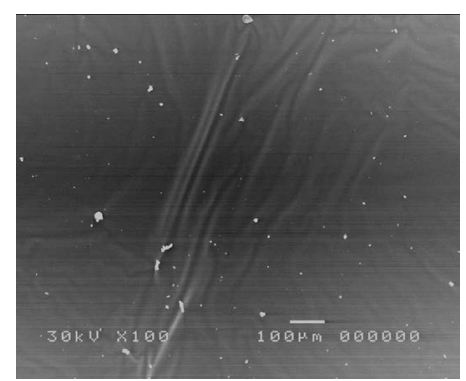

(c)

Figure 1. Scanning electron microscope (SEM) of base binder (a), binder modified with 7\% PMMA1 and (c) binder modified with 7\% PMMA2. (a) SEM of base binder; (b) SEM of binder modified with 7\% PMMA1; (c) SEM of biner modified with 7\% PMMA2.

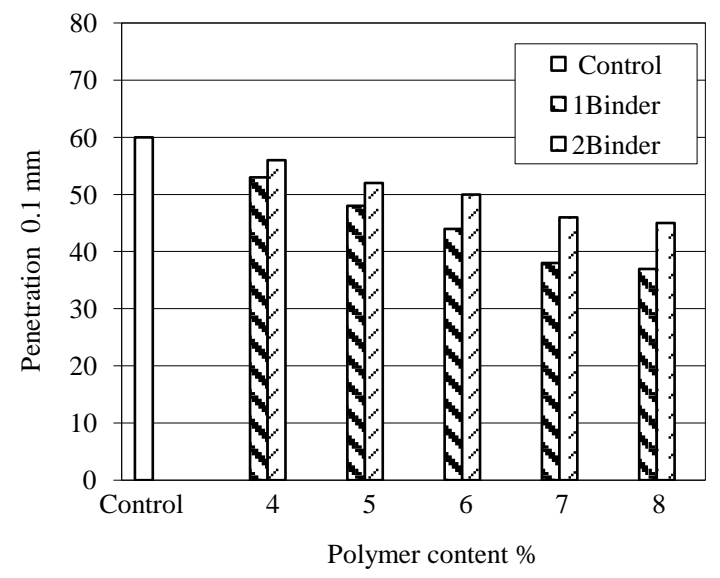

Figure 2. Effect of modifier type and modifier content on penetration value.

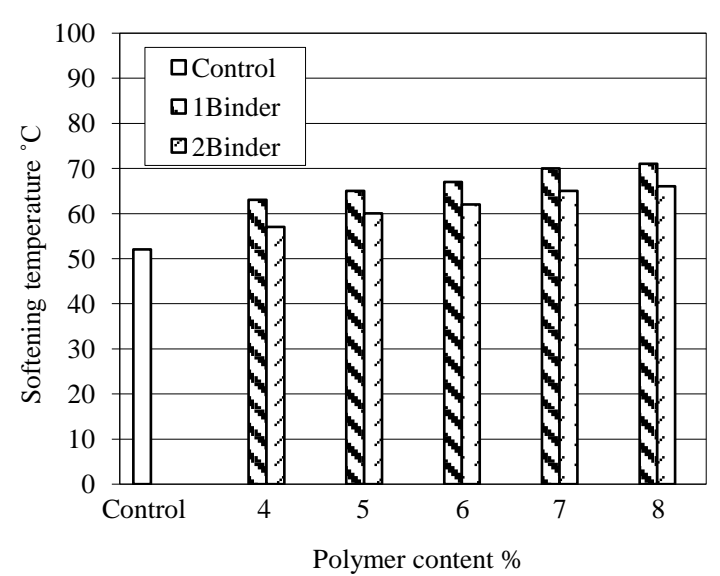

Figure 3. Effect of modifier type and modifier content on softening temperature.

results that with the increase of molecular weight of polymer added to asphalt, the softening point value decreases, and also as the polymer content increases, the softening point increases. This increase ranges from $11^{\circ} \mathrm{C}$ to $18^{\circ} \mathrm{C}$ with the addition of $4 \%$ to $7 \%$ of PMMA1, respectively, while it ranges from $5^{\circ} \mathrm{C}$ to $13^{\circ} \mathrm{C}$ with the addition of $4 \%$ to $7 \%$ of PMMA2, respectively. This phenomenon indicates that the resistance of the binder to the effect of heat is increased and it will reduce its tendency to soften in hot weather. Thus with the addition of polymer, the modified binder will be less susceptible to temperature changes. 


\subsection{Kinematic Viscosity}

Figure 4 and Figure 5 indicate that the modified asphalt kinematic viscosities at $135^{\circ} \mathrm{C}$ and $150^{\circ} \mathrm{C}$ have increased the values compared to unmodified binder. This increase ranges from $90 \%$ to $161 \%$ with the addition of $4 \%$ to $7 \%$ of PMMA1, respectively and ranges from 1.04 to 1.84 times with the addition of $4 \%$ to $7 \%$ of PMMA2, respectively at $135^{\circ} \mathrm{C}$, compared with the unmodified binder. At $150^{\circ} \mathrm{C}$ the kinematic viscosity increased by an average of $62 \%$ and $132 \%$ for asphalt modified with $4 \%$ and $7 \%$ of PMMA1, respectively. The maximum increment occurred with PMMA2, ranging from $83 \%$ to $166 \%$ for asphalt modified with $4 \%$ and $7 \%$ of polymer, respectively compared with the unmodified binder. The increase in the viscosity value at high temperature is a good property with respect to rutting resistance.

\subsection{Marshall Stability Tests}

The results of Marshall stability tests for each of the mixtures are shown in Figure 6. In general, the Marshall stability for the different modified mixtures increased as compared with unmodified mixtures. Also, The Marshall Stability of the modified mixtures increases with increasing the polymer percent. This might be due to the increase in the viscosity of the modified bitumen mixtures which led to the formation of a thicker mixture film in asphalt. This would lead to longer service life and more flexible pavement. The stability of the modified mixes increased from $12 \%$ to $28 \%$ with the addition of $4 \%$ to $7 \%$ of PMMA1, respectively and from $3 \%$ to $14 \%$ with the addition of $4 \%$ to $7 \%$ of PMMA2 respectively, compared with the control mix made from the same dense grade aggregate. The highest stability values were obtained with mixtures modified with PMMA1.

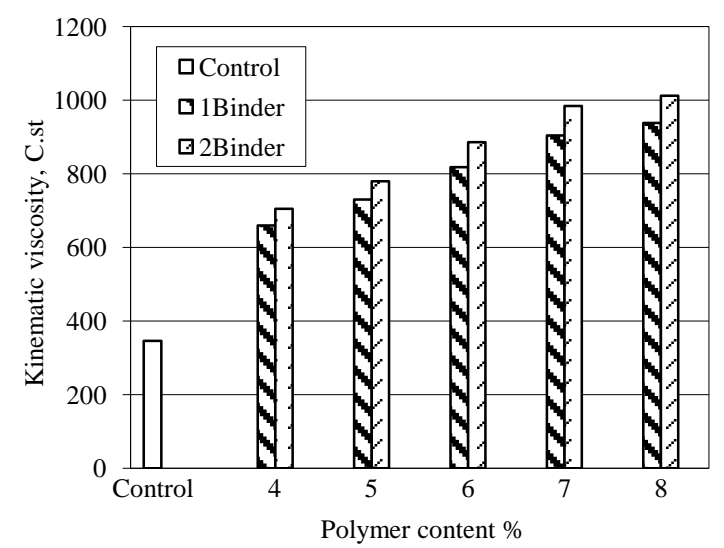

Figure 4. Effect of modifier type and modifier content on kinematic viscosity at $135^{\circ} \mathrm{C}$.

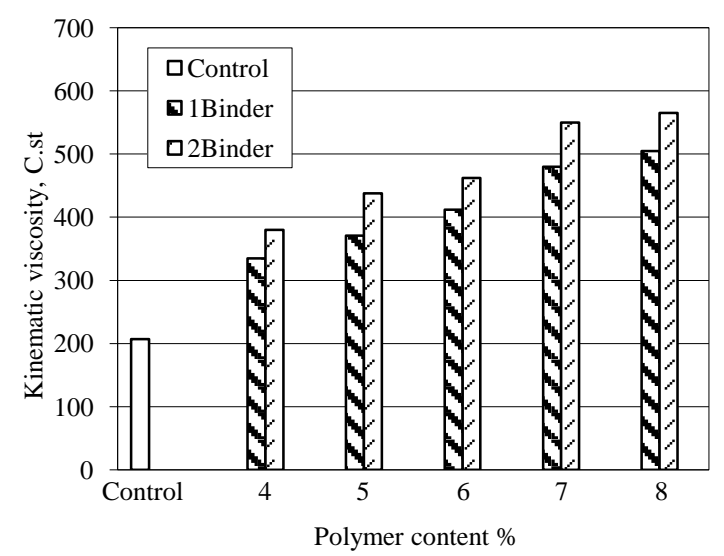

Figure 5. Effect of modifier type and modifier content on kinematic viscosity at $150^{\circ} \mathrm{C}$. 


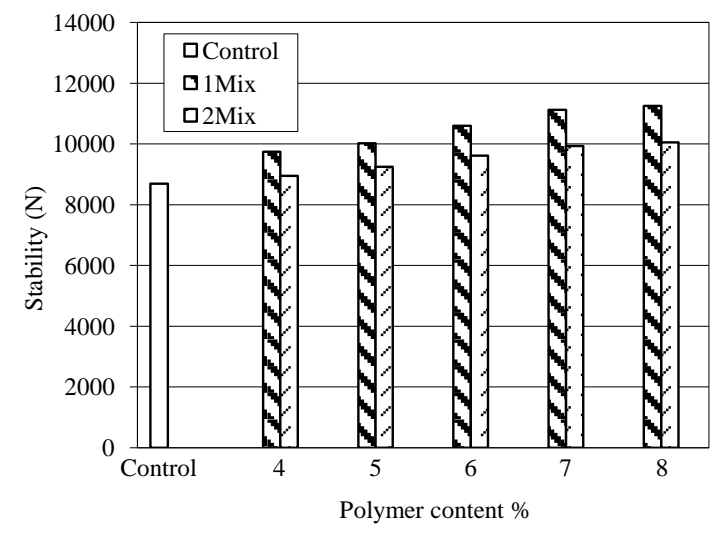

Figure 6. Effect of modifier type and modifier content on stability.

\subsection{Indirect Tensile Strength}

Indirect tensile strength (ITS) results of PMMA1 mixture containing 7\% polymer were higher than the unmodified mixture as shown in Figure 7. ITS (dry) value obtained at $25^{\circ} \mathrm{C}$ for the unmodified mix is $6.8 \mathrm{~kg} / \mathrm{cm}^{2}$ while it is $12.3 \mathrm{~kg} / \mathrm{cm}^{2}$ for modified mix containing $7 \%$ polymer. This implies that the modified mix is capable of withstanding much larger tensile strains prior to cracking. The tensile strength ratio of $7 \%$ polymer mix is $90.2 \%$ compared to $88 \%$ for unmodified mix, which confirms that the $7 \%$ polymer mix is less susceptible to moisture damage in comparison to the unmodified mix.

\subsection{Resilient Modulus (RM) Test}

The results of resilient modulus tests for both unmodified and PMMA1 mix containing 7\% modifier is presented in Figure 8. It can be seen that the resilient modulus values decrease with increase in temperature from $5^{\circ} \mathrm{C}$ to $45^{\circ} \mathrm{C}$. At $5^{\circ} \mathrm{C}$ the $\mathrm{RM}$ value for $7 \%$ modifier is 0.48 times higher whereas at $45^{\circ} \mathrm{C}$ it is about 1.18 times higher as compared to the unmodified mix. This shows that $7 \%$ modifier mix is more suitable for hot climate. Moreover, MR values for the mix containing $7 \%$ modifier at all specified temperatures are higher as compared to unmodified mix, thereby indicating that the modified mix is harder than conventional 60/70 mix.

\subsection{Oxidative Ageing}

The results have recorded that after TFOT ageing Table 7, the penetration has increased. Usually the influence of oxidative ageing on the high-temperature performance of PMAs has two major sides. The increase of the hard asphalt components such as asphaltenes and resins by ageing improves the high-temperature performance of binders and declines the temperature susceptibility, while the decomposition of the polymer dispersed in asphalt after ageing leads to an opposite result. The binder with 7\% PMMA1 shows the best improvement after TFOT ageing.

\subsection{Rutting}

As shown in Table 8, a significant improvement in rutting depth (permanent deformation) was observed for the modified mixes compared to the control mixture. The percentage of decrease ranged between $44 \%$ and $65 \%$ for mixture $_{2}$ and mixture ${ }_{1}$, respectively, compared to control mix. It is important to note that the percentage of improvement for mixture ${ }_{1}$ is higher than mixture 2 . This might be due to the good mechanical properties of PMMA1.

\section{Conclusion}

In this investigation, both physical and mechanical characteristics of the control and asphalt mixtures in terms of penetration, softening point, kinematic viscosities and stability were evaluated. The indirect tensile strength, resilient modulus and permanent deformation were studied as well. A notable achievement for the examined 


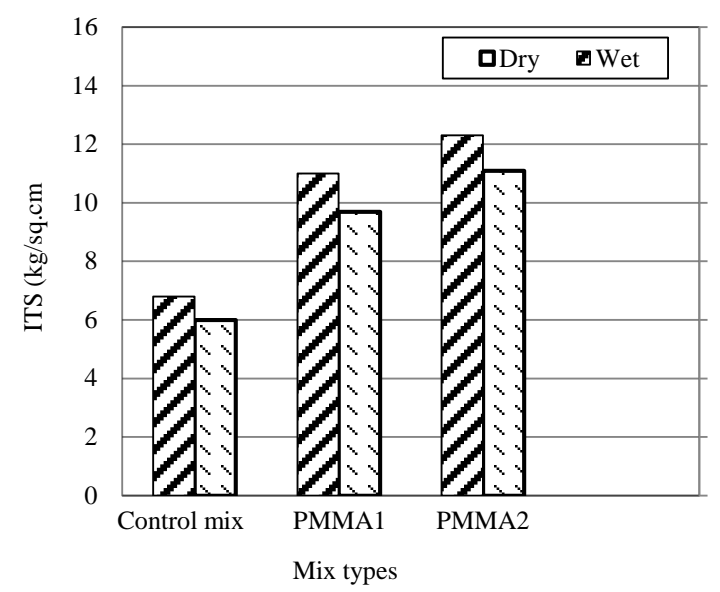

Figure 7. Effect of modifier type and modifier content on indirect tensile strength.

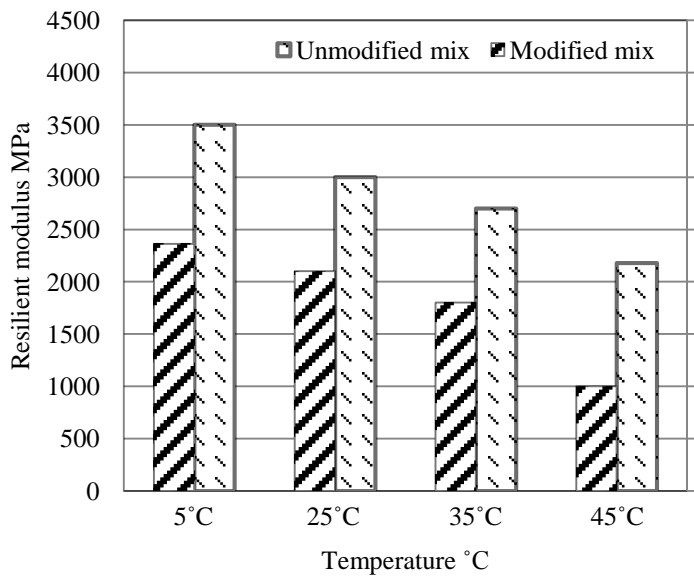

Figure 8. Resilient modulus for unmodified and $7 \%$ polymer modified asphalt mix.

Table 7. Effect of TFOT on physical properties of unmodified and modified asphalt cement 60/70.

\begin{tabular}{|c|c|c|c|c|}
\hline Binder No. & Polymer content (\%) & Loss on heating (\%) & $\begin{array}{l}\text { Penetration before } \\
\text { TFOT }(0.1 \mathrm{~mm})\end{array}$ & $\begin{array}{l}\text { Retained Penetration } \\
\text { after TFOT (\%) }\end{array}$ \\
\hline \multirow[t]{3}{*}{ Control } & 0 & 0.190 & 60 & 69 \\
\hline & 4 & 0.16 & 53 & 79 \\
\hline & 5 & 0.15 & 48 & 82 \\
\hline \multirow[t]{5}{*}{ PMMA1 } & 6 & 0.12 & 44 & 86 \\
\hline & 7 & 0.10 & 38 & 89 \\
\hline & 8 & 0.08 & 37 & 89 \\
\hline & 4 & 0.18 & 56 & 73 \\
\hline & 5 & 0.17 & 52 & 74 \\
\hline \multirow[t]{3}{*}{ PMMA2 } & 6 & 0.15 & 50 & 76 \\
\hline & 7 & 0.14 & 46 & 80 \\
\hline & 8 & 0.12 & 45 & 80 \\
\hline
\end{tabular}


Table 8. Rutting depth for modified and unmodified asphalt mixes.

\begin{tabular}{|c|c|c|c|c|}
\hline \multirow{2}{*}{ Tim (min) } & \multirow{2}{*}{$\begin{array}{l}\text { Wheel passes } \\
\text { number (n) }\end{array}$} & \multicolumn{3}{|c|}{ Rutting depth } \\
\hline & & Control mix & Mix 1 & Mix 2 \\
\hline 0 & 0 & 0 & 0 & 0 \\
\hline 5 & 210 & 0.0427 & 0.0080 & 0.0191 \\
\hline 10 & 420 & 0.0826 & 0.0200 & 0.0311 \\
\hline 15 & 630 & 0.1022 & 0.0308 & 0.0502 \\
\hline 20 & 840 & 0.1305 & 0.0333 & 0.0639 \\
\hline 25 & 1050 & 0.1665 & 0.0453 & 0.0849 \\
\hline 30 & 1260 & 0.1903 & 0.0635 & 0.1006 \\
\hline 35 & 1470 & 0.2153 & 0.0730 & 0.1117 \\
\hline 40 & 1680 & 0.2211 & 0.0790 & 0.1168 \\
\hline 45 & 1890 & 0.2303 & 0.0802 & 0.1289 \\
\hline 50 & 2100 & 0.2305 & 0.0810 & 0.1290 \\
\hline 55 & 2310 & 0.2305 & 0.0810 & 0.1290 \\
\hline 60 & 2520 & 0.2305 & 0.0810 & 0.1290 \\
\hline
\end{tabular}

Mix1: control binder with PMMA1, Mix2: control binder with PMMA2.

properties was observed such as a good compatibility of the polymers with the base bitumen especially PMMA1, increasing the softening point and decreasing penetration and viscosity. In addition the stability and tensile strength increase with increasing the PMMA1 percent. The asphalt binder with PMMA1 shows the best improvement after TFOT ageing. And finally, significant improvement in permanent deformation was observed for the modified mixtures with PMMA1compared to the control mixture.

\section{References}

[1] Zhang, H.L., Jia, X.J., Yu, J.Y. and Xue, L.H. (2013) Effect of Expanded Vermiculite on Microstructures and Aging Properties of Styrene-Butadiene-Styrene Copolymer Modified Bitumen. Construction and Building Materials, 40, 224-230. http://dx.doi.org/10.1016/j.conbuildmat.2012.09.103

[2] Zhang, F. and Yu, J.Y. (2010) Research for High-Performance SBR Compound Modified Asphalt. Construction and Building Materials, 24, 410-418. http://dx.doi.org/10.1016/j.conbuildmat.2009.10.003

[3] Martin, J., Dusan, B., Daryl, M. and Ludo, Z. (2013) Preparation and Properties of Conventionalasphalt Modified by Physical Mixtures of Linear SBS and Montmorillonite Clay. Construction and Building Materials, 38, 759-765. http://dx.doi.org/10.1016/j.conbuildmat.2012.09.043

[4] Al-Hadidy, A.I., Tan, Y.Q. and Ayman, T.H. (2011) Starch as a Modifier Forasphalt Paving Materials. Construction and Building Materials, 25, 14-20. http://dx.doi.org/10.1016/j.conbuildmat.2010.06.062

[5] Peiliang, C., Peijun, X., Mingliang, X. and Shuanfa, C. (2013) Investigation Ofasphalt Binder Containing Various Crumb Rubbers Andasphalts. Construction and Building Materials, 40, 632-641. http://dx.doi.org/10.1016/j.conbuildmat.2012.11.063

[6] Karim, G., Azam, J.A. and Mahsa, N. (2012) Statistical Investigation on Physical-Mechanical Properties of Base and Polymer Modified Bitumen Using Artificial Neural Network. Construction and Building Materials, 37, 822-831. http://dx.doi.org/10.1016/j.conbuildmat.2012.08.011

[7] Moatasim, A., Cheng, P.F. and Al-Hadidy, A.I. (2011) Laboratory Evaluation of HMA with High Density-Polyethylene as a Modifier. Construction and Building Materials, 25, 2764-2770. http://dx.doi.org/10.1016/j.conbuildmat.2010.12.037

[8] Zhang, H.Y., Wu, X.W., Cao, D.W., Zhang, Y.J. and He, M. (2013) Effect of Linear Low Density-Polyethylenegrafted with Maleic Anhydride (LLDPE-g-MAH) on Properties of Highdensity-Polyethylene/Styrene-Butadiene-Styrene (HDPE/SBS) Modified Asphalt. Construction and Building Materials, 47, 192-198.

http://dx.doi.org/10.1016/j.conbuildmat.2013.04.047 
[9] Esmaeil, A., Majid, Z., Mohamed, R.K., Mahrez, A. and Payam, S. (2011) Using Waste Plastic Bottles as Additive for Stone Masticasphalt. Materials \& Design, 32, 4844-4849. http://dx.doi.org/10.1016/j.matdes.2011.06.016

[10] Polacco, G., Berlincioni, S., Biondi, D., Stastna, J. and Zanzotto, L. (2005) Asphalt Modification with Different Polyethylene-Based Polymers. European Polymer Journal, 41, 2831-2844. http://dx.doi.org/10.1016/j.eurpolymj.2005.05.034

[11] Kim, H., Lee, S.J. and Amirkhanian, S.N. (2011) Rheology of Warm Mix Asphalt Binders with Aged Binders. Construction and Building Materials, 25, 183-189. http://dx.doi.org/10.1016/j.conbuildmat.2010.06.040

[12] Edwards, Y., Tasdemir, Y. and Isacsson, U. (2007) Rheological Effects of Commercial Waxes and Polyphosphoric Acid in Bitumen 160/220-High and Medium Temperature Performance. Construction and Building Materials, 21, 1899-1908. http://dx.doi.org/10.1016/j.conbuildmat.2006.07.012

[13] Merusi, F. and Giuliani, F. (2011) Rheological Characterization of Wax-Modified Asphalt Binders at High Service Temperatures. Materials and Structures, 44, 1809-1820.

[14] Fawcett, A.H. and McNally, T. (2001) Studies on Blends of Acetate and Acrylic Functional Polymers with Bitumen. Macromolecular Materials and Engineering, 286, 126-137. http://dx.doi.org/10.1002/1439-2054(20010201)286:2<126::AID-MAME126>3.0.CO;2-X

[15] Airey, G.D. (2002) Rheological Evaluation of Ethylene Vinyl Acetate Polymer Modified Bitumens. Construction and Building Materials, 16, 473-487. http://dx.doi.org/10.1016/S0950-0618(02)00103-4

[16] Iqbal, M.H., Hussein, I.A., Wahhab, H. and Amin, M.B. (2006) Rheological Investigation of the Influence of Acrylate Polymers on the Modification of Asphalt. Journal of Applied Polymer Science, 102, 3446-3456. http://dx.doi.org/10.1002/app.24408

[17] Evdokia, K.O., Aikaterini, B., Georgios, B. and Joannis, K.K. (2011) Poly (Sodium styrene sulfonate) Poly (methyl methacrylate) Diblock Copolymers through Direct Atom Transfer Radical Polymerization: Influence of Hydrophilic Hydrophobic Balance on Self-Organization in Aqueous Solution. European Polymer Journal, 47, 752-761. http://dx.doi.org/10.1016/j.eurpolymj.2010.09.034

[18] Marco, B., Assunta, B. and Paolo A.N. (2010) Isothermal and Non-Isothermal Polymerization of Methyl Methacrylate in Presence of Multiple Initiators. Chemical Engineering Journal, 162, 776-786. http://dx.doi.org/10.1016/j.cej.2010.06.004

[19] (1997) ASTM Standards D5-97, Standard Test Method for Penetration of Bituminous Materials: ASTM International.

[20] (2000) ASTM Standards D36-95, Standard Test Method for Softening Point of Bitumen (Ring-and-Ball Apparatus).

[21] (1995) ASTM D2170-01a, Standard Test Method for Kinematic Viscosity of Asphalts (Bitumens).

[22] (2002) ASTM D1754-97, Standard Test Method for Effect of Heat and Air on Asphaltic Materials (Thin-Film Oven Test).

[23] ASTM D1559-89, Standard Test Method for Resistance of Plastic Flow of Bituminous Mixtures Using Marshall Apparatus (Withdrawn 1998).

[24] Alexander, B., Adam, Z. and Iliya, Y. (2012) Laboratory Evaluation of Rutting Susceptibility of Polymer Modified Asphalt Mixtures Containing Recycled Pavements. Construction and Building Materials, 31, 58-66. http://dx.doi.org/10.1016/j.conbuildmat.2011.12.094

[25] AASHTO T 283-03, Standard Method of Test for Resistance of Compacted Asphalt Mixtures to Moisture-Induced Damage.

[26] Moreno, F., Sol, M., Martín, J., Pérez, M. and Rubio, M.C. (2013) The Effect of Crumb Rubber Modifier on the Resistance of Asphalt Mixes to Plastic Deformation. Materials \& Design, 47, 274-280. http://dx.doi.org/10.1016/j.matdes.2012.12.022

[27] (1995) ASTM D4123-82, Standard Test Method for Indirect Tension Test for Resilient Modulus of Bituminous Mixtures. 